\title{
Treatment and Prognosis of Solid and Cystic Brain Metastases in Patients with Non-Small-Cell Lung Cancer
}

\author{
Yi-Bing $X u^{1,2}$ \\ Yiping Zhang ${ }^{1,2}$ \\ Zhengbo Song ${ }^{1,2}$ \\ Wenxian Wang (iD ${ }^{1,2}$ \\ Lan Shao ${ }^{1,2}$ \\ 'Cancer Hospital of the University of \\ Chinese Academy of Sciences (Zhejiang \\ Cancer Hospital), Hangzhou, 310022, \\ People's Republic of China; ${ }^{2}$ Institute of \\ Cancer and Basic Medicine (IBMC), \\ Chinese Academy of Sciences, Hangzhou, \\ 310022, People's Republic of China
}

Correspondence: Lan Shao Zhejiang Cancer Hospital, No. I East Banshan Road, Hangzhou, 310022 Zhejiang Province, People's Republic of China

Tel +86 I 7826866632

Email shaolan1677@I63.com
Background: Brain metastasis (BM) is an important factor shortening the lives of patients with lung cancer. Patients with cystic BM have seldom been reported. Here, we compared the efficacy and prognosis of different therapeutic schedules for solid BM and cystic BM in patients with non-small cell lung cancer (NSCLC).

Methods: A retrospective study was conducted of 355 patients with pathologically confirmed stage IV NSCLC, all of whom had BM. We analyzed the clinical characteristics of these patients and the efficacy of targeted drugs and chemotherapy regimens.

Results: A total of 255 patients with solid BM (cohort 1) and 33 patients with cystic BM (cohort 2) had evaluable efficacy. We evaluated these 33 patients in cohort 2 . The median progression-free survival (PFS) and overall survival (OS) were 8.4 months and 23.0 months, respectively. A significant difference was observed between targeted regimens and chemotherapy treatment in terms of the PFS (12.6 months vs 6.3 months, $\mathrm{P}=0.001)$ and OS (47.9 months vs 17.0 months, $\mathrm{P}=0.007)$. Multivariate analyses showed that treatment regimen (chemotherapy) was a poor prognostic factor for PFS $(\mathrm{P}<0.05)$. Cystic BM may be more likely to occur in patients with NSCLC with genetic mutations. A difference in prognosis was observed between patients who underwent targeted treatment and chemotherapy. A significant difference in intracranial PFS was observed between cohorts (cohort 1 vs cohort 2: 15.4 months vs 9.9 months, $\mathrm{P}=0.015)$, and this advantage was clear in patients who did not receive targeted therapies $(11.7$ months vs 6.5 months, $\mathrm{P}=0.003)$. However, the OS in patients with targeted therapies in cohort 2 was significantly longer than that in cohort 1 (23.4 months vs 47.9 months, $\mathrm{P}=0.013$ ).

Conclusion: Patients with NSCLC, particularly those who develop cystic BM, should be genetically tested as much as possible to find out more suitable drug therapies.

Keywords: cystic brain metastases, tyrosine kinase inhibitors, chemotherapy, radiation therapy, lung cancer

\section{Introduction}

Lung cancer is the most common cause of cancer death throughout the world. ${ }^{1}$ Brain metastasis (BM), the most common intracranial tumor, manifests in 10-20\% of patients with non-small cell lung cancer (NSCLC) at diagnosis. ${ }^{2,3}$ Approximately $30-50 \%$ of patients with NSCLC develop BM during their disease course. ${ }^{4}$ Patients with BM commonly have poor prognosis, and untreated patients have a median survival of just $1-2$ months. ${ }^{5}$ Whole brain radiotherapy (WBRT) increases the median survival to 4-6 months. ${ }^{6}$ The development of treatments for BM, including surgery, WBRT, stereotactic radiotherapy, chemotherapy and targeted therapy, has 
greatly extended the survival of patients with $\mathrm{BM}^{7}$ Stereotactic radiosurgery (SRS) is a new treatment method applied in select conditions of relatively oligometastasis (five or fewer BMs). ${ }^{8}$

Cystic BM is uncommon, and cystic brain lesions are often deemed unsuitable for radiation, because of cystic lesions' insensitivity to radiotherapy and their large volume. Therefore, appropriate treatment strategies for cystic BM are desperately needed. However, the efficacy and prognosis according to different treatment options in patients with NSCLC and cystic BM have seldom been reported. Therefore, we retrospectively evaluated the response and survival to different drug treatments in patients with cystic BM and NSCLC.

\section{Patients and Methods}

\section{Patient Characteristics}

We reviewed 355 patients with NSCLC with BM at our center from January 2012 to June 2019, and then retrospectively reviewed the clinical records, treatment regimens and survival of patients with BM. The inclusion criteria were as follows: (1) definite histopathological diagnosis of NSCLC, (2) BM, either newly diagnosed or currently treated, and (3) absence of meningeal metastases. Ultimately, 312 patients $(312 / 355,87.9 \%)$ who developed solid BM and 43 patients $(43 / 355,12.1 \%)$ who developed cystic BM were included and analyzed in our study.

\section{Radiological Data}

We defined cystic BM by a volume of cystic lesions greater than $50 \%$ of the total volume. Contrast-enhanced MRI is necessary for diagnosing cystic BM. The cystic components revealed hypointensity in T1-weighted images, hyperintensity in T2-weighted images and no enhancement. Enhanced MRI was performed at 1 month or 2 cycles after the initial treatment, and every 2 months or 2-4 cycles after the brain lesions became stable.

\section{Treatment and Response Assessment}

We collected data on all patients, including systemic treatment and efficacy, and brain treatment options and efficacy. The systemic treatment included targeted therapy (gefitinib $250 \mathrm{mg} / \mathrm{d}$, icotinib $125 \mathrm{mg} / \mathrm{tid}$, erlotinib $150 \mathrm{mg} / \mathrm{d}$, afatinib $40 \mathrm{mg} / \mathrm{d}$, crizotinib $250 \mathrm{mg} / \mathrm{bid}$ and osimertinib $80 \mathrm{mg} / \mathrm{d}$ ) and chemotherapy (chemotherapy regimens and doses based on international standards). The brain treatment options were WBRT, gamma knife and surgery. All patients underwent imaging examinations after two courses of chemotherapy or every $4 \pm 1$ weeks for the first 2 months of epidermal growth factor receptor (EGFR)-tyrosine kinase inhibitor (TKI) treatment. Response to systemic therapies was assessed locally by each investigator by using Response Evaluation Criteria in Solid Tumors (RECIST v1.1), and included complete response (CR), partial response (PR), stable disease (SD) and progressive disease. The ORR was defined as the sum of CR and PR. The disease control rate (DCR) was defined as the sum of the objective response and stabilization rates $(\mathrm{CR}+\mathrm{PR}+\mathrm{SD})$.

\section{Follow-Up and Statistical Analysis}

Progression-free survival (PFS) was defined as the period from the initial date of drug treatment after diagnosis with $\mathrm{BM}$ to the date of confirmation of disease progression, as evaluated by RECIST v1.1, or death. Intracranial progression-free survival (iPFS) was defined as the time from using drug treatment after diagnosis with BM until intracranial progression. OS was measured from the date of confirmed stage IV NSCLC to death or the last follow-up evaluation. The last follow-up date was November 10th, 2020.

Statistical analysis was performed in SPSS version 25.0 (SPSS, Chicago, IL, USA). The survival estimates were analyzed with the Kaplan-Meier method. Multivariate survival analysis for prognostic factors and cystic BM was performed by using Cox regression and the forward likelihood ratio method. A two-sided test yielding $\mathrm{P}<0.05$ was considered statistically significant.

\section{Results}

\section{Clinicopathologic Characteristics}

In our study, 312 patients $(312 / 355,87.9 \%)$ developed solid BM, and 43 patients $(43 / 355,12.1 \%)$ developed cystic BM. Among them, 255 patients with solid BM (cohort 1) and 33 patients with cystic BM (cohort 2) had evaluable efficacy. There were 143 men and 112 women in cohort 1, with a mean age of 58 years (range, 21-80 years). Most cases $(221 / 255,86.7 \%)$ were adenocarcinomas. A total of $173(67.8 \%)$ patients received additional brain interventions, including 13 surgeries, $151 \mathrm{WBRT}$ and 30 SRS. The majority of them $(173 / 255,67.8 \%)$ were observed supratentorial lesions only, fewer patients (16/ $255,6.3 \%$ ) were only observed infratentorial lesions, and 
the other patients $(66 / 255,25.9 \%)$ developed BM in both supratentorial and infratentorial lesions.

We carefully analyzed the characteristics of the patients in cohort 2, comprising 19 men and 14 women. The mean age of the patients was 57 years (range, 33-71 years). Ten patients had three or more cystic BM lesions, 7 patients had two lesions and 16 patients had a single lesion. A total of $20(60.6 \%)$ patients developed BM only in supratentorial position, while $5(15.2 \%)$ patients developed BM only in infratentorial position, and the combined lesions were observed at $8(24.2 \%)$ patients. The mode of onset was synchronous in $25(75.8 \%)$ and metachronous in $8(24.2 \%)$ patients. Four patients had received surgery, and 16 had brain radiotherapy. WBRT was given in 25 patients, and SRS was given in 4 patients. More than half the patients (19/33, 57.6\%) had significant neurologic symptoms, including headaches, dizziness, vomiting, muscle weakness or lalopathy. The cases included 26 adenocarcinomas and 7 squamous cell carcinomas. Twenty patients had EGFR or anaplastic lymphoma kinase (ALK) gene mutations, and 13 patients were gene negative or undetected. Among patients undergoing genetic detection, the incidence of gene mutation was $76.9 \%(20 / 26)$.

We collected the data for the 288 patients in the two cohorts and compared their characteristics in Table 1. We also compared the characteristics between patients in cohort 2 who received targeted drugs and chemotherapy in Table 2.

\section{Effect Assessment and Local Control}

According to our follow-up, the ORR between cohort 1 and cohort 2 was 35.3\% (90/255) and 51.5\% (17/33), respectively $(\mathrm{P}=0.070)$. The DCR was $89.2 \%(227 / 255)$ and $87.9 \%(29 / 33)$, respectively $(\mathrm{P}=0.844)$. In cohort 1,88 patients with EGFR/ALK gene mutation had TKI targeted treatment, 12 patients without EGFR/ALK gene mutation had TKI targeted treatment and 155 patients received chemotherapy. The ORR for patients receiving targeted regimens and chemotherapy treatment was $67.0 \%(59 / 88)$ and $18.1 \%(28 / 155)$, respectively $(\mathrm{P}<0.001)$. The DCR was $94.3 \%(83 / 88)$ and $87.1 \%(135 / 155)$, respectively $(\mathrm{P}=0.075)$. For patients in cohort 2, 14 patients with EGFR/ALK gene mutation had TKI targeted treatment, and 19 patients received chemotherapy. For brain radiotherapy, 4 of 14 patients with EGFR/ALK mutations received radiotherapy, and 12 of 19 patients received chemotherapy had brain radiotherapy. The ORR for targeted regimens and chemotherapy treatment was $78.6 \%(11 / 14)$
Table I Baseline Characteristics of 255 Patients with NSCLC with Solid Metastases and 33 Patients with NSCLC with Cystic Metastases

\begin{tabular}{|c|c|c|c|}
\hline Characteristics & $\begin{array}{l}\text { Cohort I } \\
(n=255)\end{array}$ & $\begin{array}{l}\text { Cohort } 2 \\
(n=33)\end{array}$ & $P$ value \\
\hline $\begin{array}{l}\text { Sex } \\
\text { Male } \\
\text { Female }\end{array}$ & $\begin{array}{l}\text { I43(56.1\%) } \\
\text { II } 2(43.9 \%)\end{array}$ & $\begin{array}{l}19(57.6 \%) \\
14(42.4 \%)\end{array}$ & 0.870 \\
\hline $\begin{array}{r}\text { Age, y } \\
<65 \\
\geq 65\end{array}$ & $\begin{array}{l}188(73.7 \%) \\
67(26.3 \%)\end{array}$ & $\begin{array}{l}30(90.9 \%) \\
3(9.1 \%)\end{array}$ & 0.030 \\
\hline $\begin{array}{l}\text { Smoking history } \\
\text { No } \\
\text { Yes }\end{array}$ & $\begin{array}{l}\text { I39(54.5\%) } \\
\text { II } 6(45.5 \%)\end{array}$ & $\begin{array}{l}14(42.4 \%) \\
19(57.6 \%)\end{array}$ & 0.190 \\
\hline $\begin{array}{l}\text { ECOG score } \\
\qquad \begin{array}{l}0-1 \\
\geq 2\end{array}\end{array}$ & $\begin{array}{l}180(70.6 \%) \\
75(29.4 \%)\end{array}$ & $\begin{array}{l}23(69.7 \%) \\
10(30.3 \%)\end{array}$ & 0.916 \\
\hline $\begin{array}{l}\text { Histologic subtype } \\
\text { Squamous } \\
\text { Adenocarcinoma }\end{array}$ & $\begin{array}{l}34(13.3 \%) \\
221(86.7 \%)\end{array}$ & $\begin{array}{l}7(21.2 \%) \\
26(78.8 \%)\end{array}$ & 0.223 \\
\hline $\begin{array}{l}\text { Gene mutation status } \\
\text { EGFR mutation } \\
\text { ALK positive } \\
\text { Negative }\end{array}$ & $\begin{array}{l}149(58.4 \%) \\
10(3.9 \%) \\
96(37.7 \%)\end{array}$ & $\begin{array}{l}16(48.5 \%) \\
4(12.1 \%) \\
13(39.4 \%)\end{array}$ & 0.846 \\
\hline $\begin{array}{l}\text { Number of brain } \\
\text { metastases } \\
\quad \begin{array}{l}1 \\
2 \\
\geq 3\end{array}\end{array}$ & $\begin{array}{l}88(34.5 \%) \\
44(17.3 \%) \\
123(48.2 \%)\end{array}$ & $\begin{array}{l}16(48.5 \%) \\
7(21.2 \%) \\
10(30.3 \%)\end{array}$ & 0.144 \\
\hline $\begin{array}{l}\text { Additional brain } \\
\text { intervention } \\
\text { Yes } \\
\text { No }\end{array}$ & $\begin{array}{l}173(67.8 \%) \\
82(32.2 \%)\end{array}$ & $\begin{array}{l}28(84.8 \%) \\
5(15.2 \%)\end{array}$ & 0.045 \\
\hline $\begin{array}{l}\text { TKI drugs treatment } \\
\text { Yes } \\
\text { No }\end{array}$ & $\begin{array}{l}100(39.2 \%) \\
155(60.8 \%)\end{array}$ & $\begin{array}{l}14(51.2 \%) \\
19(48.8 \%)\end{array}$ & 0.723 \\
\hline
\end{tabular}

and $31.6 \%(6 / 19)$, respectively $(\mathrm{P}=0.013)$. The $\mathrm{DCR}$ was $100 \%(14 / 14)$ and $78.9 \%(15 / 19)$, respectively $(\mathrm{P}=0.119)$.

In Figure 1, we present a typical case with EGFR mutated NSCLC with cystic BM; the patient had a good response after EGFR-TKI treatment.

\section{Progression-Free Survival}

The median progression-free survival (PFS) of 255 patients in cohort 1 was 5.6 months, and a significant difference was observed between targeted regimens and 
Table 2 Baseline Characteristics of Patients According to Treatment Regimens in Cohort 2

\begin{tabular}{|c|c|c|c|}
\hline & $\begin{array}{l}\text { Targeted } \\
\text { Treatment } \\
(n=14)\end{array}$ & $\begin{array}{l}\text { Chemotherapy } \\
\text { Treatment } \\
(n=19)\end{array}$ & $P$ value \\
\hline $\begin{array}{l}\text { Sex } \\
\qquad \text { Male } \\
\text { Female }\end{array}$ & $\begin{array}{l}5(35.7 \%) \\
9(64.3 \%)\end{array}$ & $\begin{array}{l}14(73.7 \%) \\
5(26.3 \%)\end{array}$ & 0.029 \\
\hline $\begin{array}{r}\text { Age, y } \\
<65 \\
\geq 65\end{array}$ & $\begin{array}{l}12(85.7 \%) \\
2(14.3 \%)\end{array}$ & $\begin{array}{l}\text { I8 (94.7\%) } \\
\text { I (5.3\%) }\end{array}$ & 0.561 \\
\hline $\begin{array}{l}\text { Smoking history } \\
\text { No } \\
\text { Yes }\end{array}$ & $\begin{array}{l}9(64.3 \%) \\
5(35.7 \%)\end{array}$ & $\begin{array}{l}5(26.3 \%) \\
14(73.7 \%)\end{array}$ & 0.029 \\
\hline $\begin{array}{l}\text { ECOG score } \\
0-1 \\
2\end{array}$ & $\begin{array}{l}10 \text { (7I.4\%) } \\
4(28.6 \%)\end{array}$ & $\begin{array}{l}13(68.4 \%) \\
6(31.6 \%)\end{array}$ & 1.000 \\
\hline $\begin{array}{l}\text { Histologic } \\
\text { subtype } \\
\quad \text { Squamous } \\
\text { Adenocarcinoma }\end{array}$ & $\begin{array}{l}0(0 \%) \\
14(100.0 \%)\end{array}$ & $\begin{array}{l}7(36.8 \%) \\
12(63.2 \%)\end{array}$ & 0.013 \\
\hline $\begin{array}{l}\text { Number of brain } \\
\text { lesions } \\
\text { I-2 } \\
\geq 3\end{array}$ & $\begin{array}{l}\text { II (78.6\%) } \\
3 \text { (2I.4\%) }\end{array}$ & $\begin{array}{l}12(63.2 \%) \\
7(36.8 \%)\end{array}$ & 0.455 \\
\hline $\begin{array}{l}\text { If brain } \\
\text { radiotherapy } \\
\text { No } \\
\text { Yes }\end{array}$ & $\begin{array}{l}10 \text { (7I.4\%) } \\
4(28.6 \%)\end{array}$ & $\begin{array}{l}7(36.8 \%) \\
12(63.2 \%)\end{array}$ & 0.049 \\
\hline $\begin{array}{l}\text { If anti-vascular } \\
\text { drugs } \\
\text { No } \\
\text { Yes }\end{array}$ & $\begin{array}{l}12(85.7 \%) \\
2(14.3 \%)\end{array}$ & $\begin{array}{l}\text { I } 8 \text { (94.7\%) } \\
\text { | (5.3\%) }\end{array}$ & 0.561 \\
\hline
\end{tabular}

chemotherapy treatments (10.5 months vs 4.3 months, $\mathrm{P}<0.001)$.

The PFS of the 33 patients in cohort 2 was 8.4 months, and a significant difference was found between targeted regimens and chemotherapy treatment (12.6 months vs 6.3 months, $\mathrm{P}=0.001$ ) (Figure 2A). Among these patients, 22 had brain lesion development first or simultaneous progression of brain and extra-cerebral lesions; 11 had extra-cerebral lesion progression first. The PFS between patients with brain lesion progression first and those with extra-cerebral lesions first was significantly different (6.2 months vs 13.0 months,
$\mathrm{P}=0.017)$. We then explored intracerebral progressionfree survival (iPFS) in patients who had brain lesion development first or had simultaneous progression of brain and extra-cerebral lesions. The median iPFS of these 22 patients was 6.2 months, and significant difference was found between targeted regimens and chemotherapy treatment (8.4 months vs 6.0 months, $\mathrm{P}=0.042$ ) (Figure 2B). The iPFS did not significantly differ between patients with brain radiotherapy (6.5 months) or without radiotherapy (6.2 months; $\mathrm{P}=0.516)$. There was no significant difference between patients with different BM positions in terms of the PFS (supratentorial lesions only vs infratentorial lesions vs both: 8.4 months vs 8.2 months vs $6.5 ; \mathrm{P}=0.641$ ).

In a multivariate analysis, for patients in cohort 2 , treatment regimens $(\mathrm{P}=0.002)$ and brain lesions progression first $(\mathrm{P}=0.022)$ were independent prognostic factors for PFS. There was no significant association of PFS with sex $(\mathrm{P}=0.617)$, age $(\mathrm{P}=0.239)$, smoking history $(\mathrm{P}=0.316)$, pathological type $(\mathrm{P}=0.324)$, PS score $(\mathrm{P}=0.930)$, number of brain metastasis lesions $(\mathrm{P}=0.325)$, use of anti-vascular drugs $(\mathrm{P}=0.126)$ and brain radiotherapy $(\mathrm{P}=0.806)$.

The PFS of cohort 2 was longer than of cohort 1, but the difference was not significant $(\mathrm{P}=0.234)$. However, the iPFS was significantly longer for patients in cohort 1 (cohort 1 vs cohort 2: 15.4 months vs 9.9 months, $\mathrm{P}=0.015$ ) (Figure $3 \mathrm{~A}$ ), and this advantage was clear in patients who did not receive targeted treatment regimens (cohort 1 vs cohort 2: 11.7 months vs 6.5 months, $\mathrm{P}=0.003$ ) (Figure 3B). For patients receiving targeted therapies, there was no significant difference in iPFS between cohorts (cohort 1 vs cohort 2: 21.4 months vs 23.1 months, $\mathrm{P}=0.585)$.

\section{Overall Survival}

The median overall survival (OS) of the 255 patients in cohort 1 was 18.7 months, and that of the 33 patients in cohort 2 was 23.0 months. There was no significant difference in median OS between cohort 1 and cohort 2 $(\mathrm{P}=0.162)$. However, subgroup analysis showed a significant difference in median OS between the patients who received targeted regimens in the two cohorts (cohort 1 vs cohort $2=23.4$ vs 47.9 months; $\mathrm{P}=0.013$ ) (Figure 4).

We further statistically analyzed the data for cohort 2 and found a significant difference between targeted regimen and chemotherapy treatment (47.9 months vs 17.0 months, $\mathrm{P}=0.007$ ) (Figure 5). The OS for patients with brain lesion progression first was 17.5 months and that for patients with extra-cerebral lesions first was 25.4 

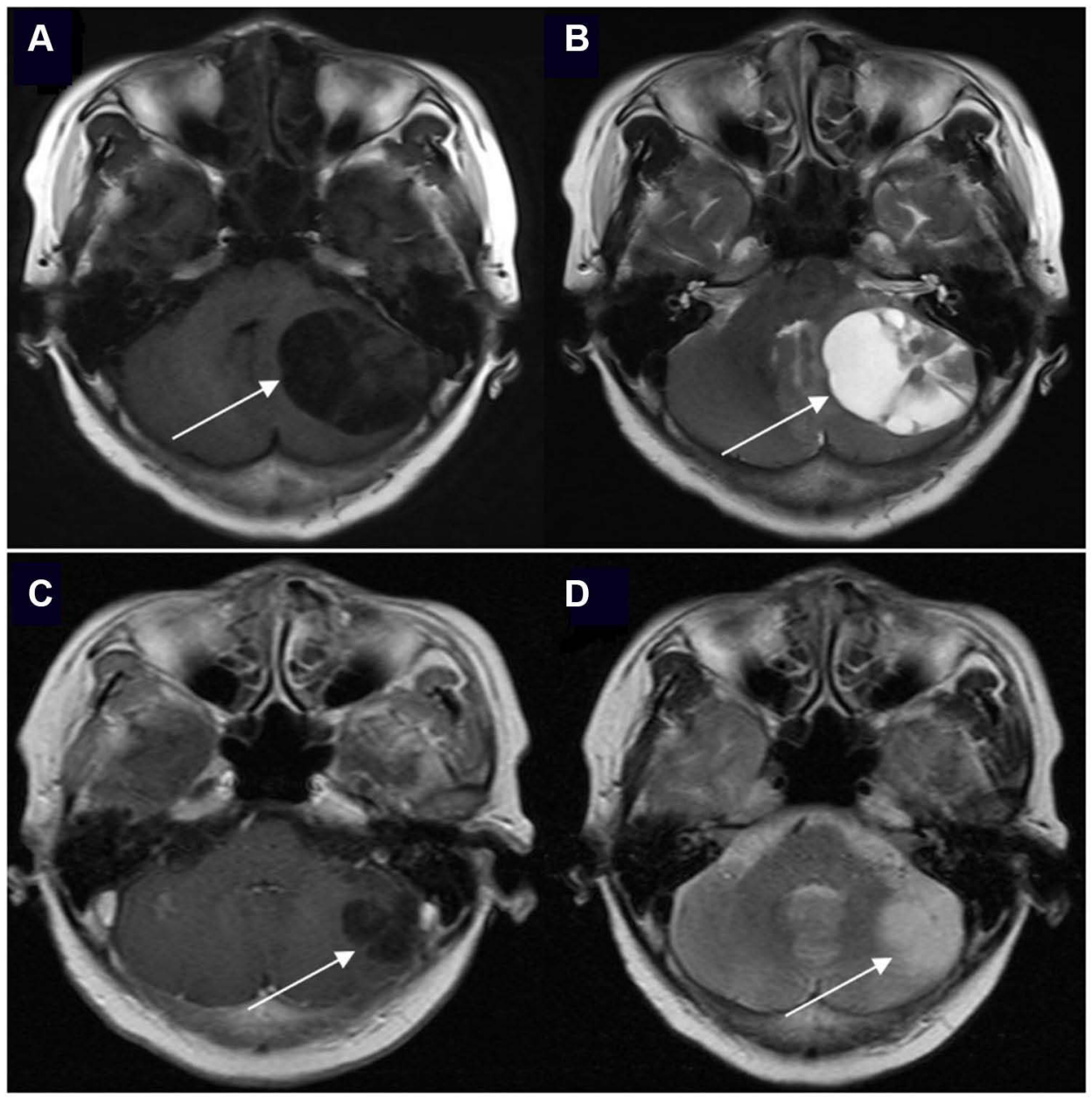

Figure I The brain enhanced MRI of a 6 I-year-old woman with non-small cell lung cancer and EGFR 2IL858R mutation before and after EGFR-TKI treatment. The positions indicated by the arrows are the lesions. (A) Contrast-enhanced TI-weighted MR image at baseline. (B) Contrast-enhanced T2-weighted MR image at baseline. (C) Contrastenhanced TI-weighted MR image after icotinib (first-generation EGFR-TKI) treatment and whole brain radiotherapy (prescription dose and fraction schedule of 30Gy/ I0F) treatment for I month. (D) Contrast-enhanced T2-weighted MR image after icotinib and whole brain radiotherapy treatment for I month.

A

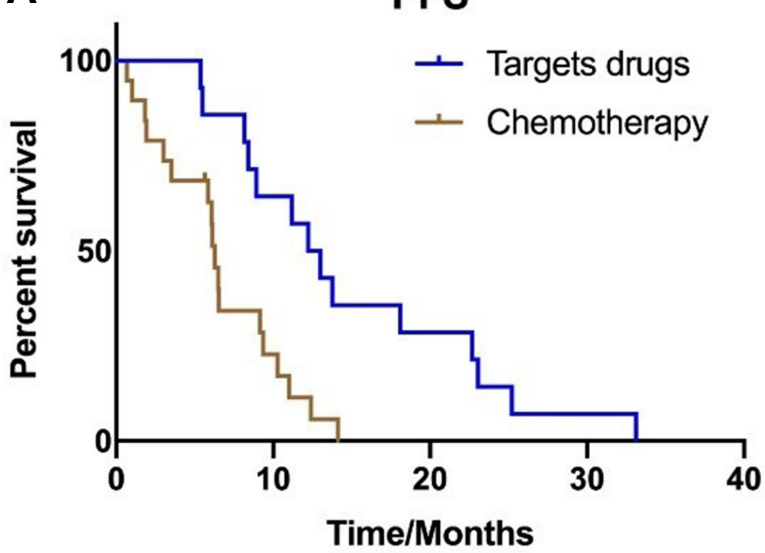

B

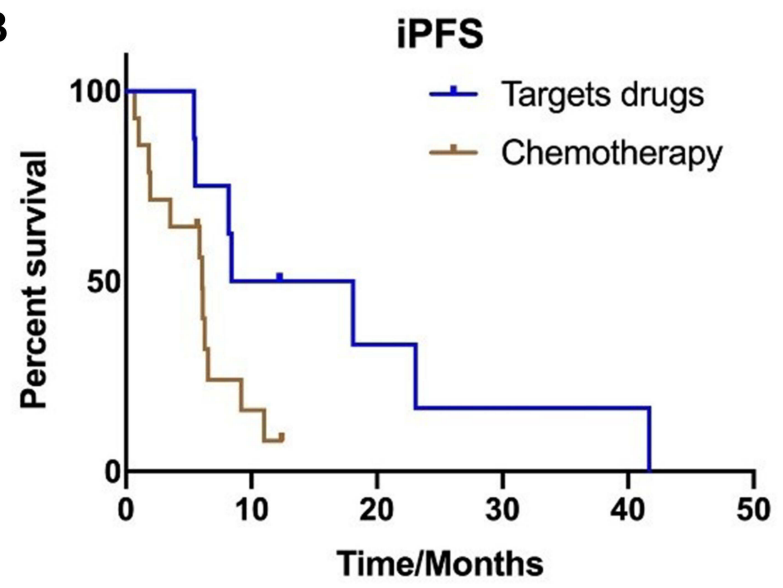

Figure 2 Kaplan-Meier estimates of progression-free survival with 33 patients in cohort 2, according to the different treatments: (A) Targeted drugs and chemotherapy treatment (12.6 months vs 6.3 months, $P=0.001)$. (B) Median iPFS between targeted regimens and chemotherapy treatment $(8.4$ months vs 6.0 months, $P=0.042)$. 

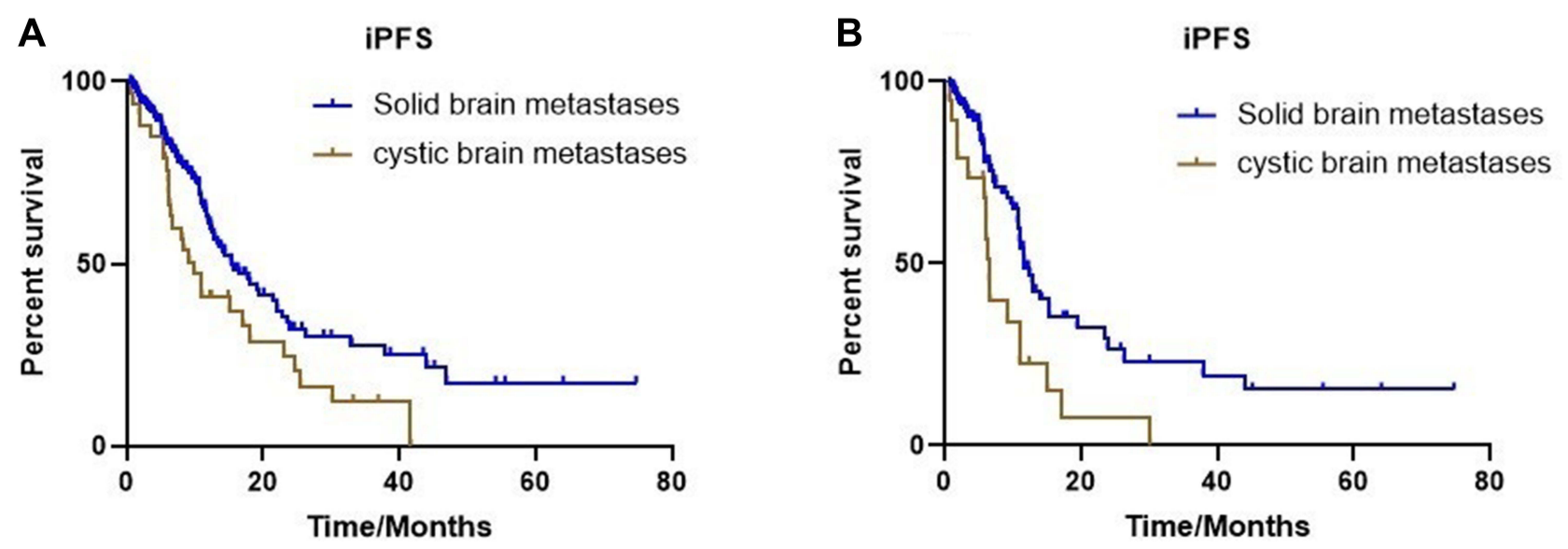

Figure 3 Kaplan-Meier estimates of intracranial progression-free survival with all patients in two cohorts, according to different types of brain metastases. (A) Solid brain metastases and cystic brain metastases ( 15.4 months vs 9.9 months, $P=0.015)$. (B) Median iPFS between solid brain metastases and cystic brain metastases without targeted therapy ( 11.7 months vs 6.5 months, $\mathrm{P}=0.003)$.

os

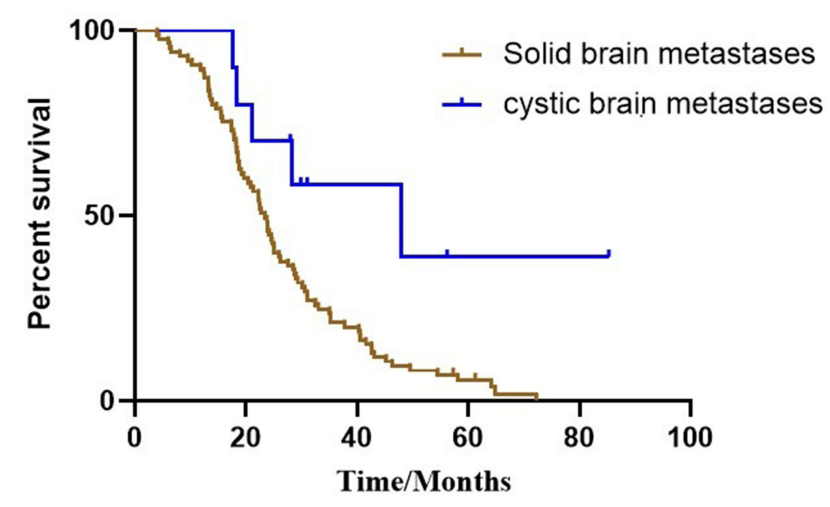

Figure 4 Kaplan-Meier estimates of overall survival in patients receiving targeted drugs, according to different types of brain metastases: solid brain metastases and cystic brain metastases ( 23.4 vs 47.9 months; $\mathrm{P}=0.013$ ).

months, $\mathrm{P}=0.127)$. The OS showed no significant difference for patients with or without radiotherapy (15.2 vs 28.3 months; $\mathrm{P}=0.178$ ). The $\mathrm{OS}$ did not significantly differ between patients with different BM positions (supratentorial lesions only vs infratentorial lesions vs both: 17.6 months vs 36.4 months vs $35.5 ; \mathrm{P}=0.269$ ).

In a multivariate analysis of cohort 2 , pathological type $(\mathrm{P}=0.005)$ was an independent prognostic factor of OS. There was no significant association of OS with sex $(\mathrm{P}=0.581)$, age $(\mathrm{P}=0.667)$, smoking history $(\mathrm{P}=0.287)$, $\mathrm{PS}$ score $(\mathrm{P}=0.943)$, treatment regimen $(\mathrm{P}=0.538)$, number of brain metastasis lesions $(\mathrm{P}=0.108)$, use of anti-vascular drugs $(\mathrm{P}=0.440)$, location of the lesion $(\mathrm{P}=0.634)$ and brain radiotherapy $(\mathrm{P}=0.928)$.

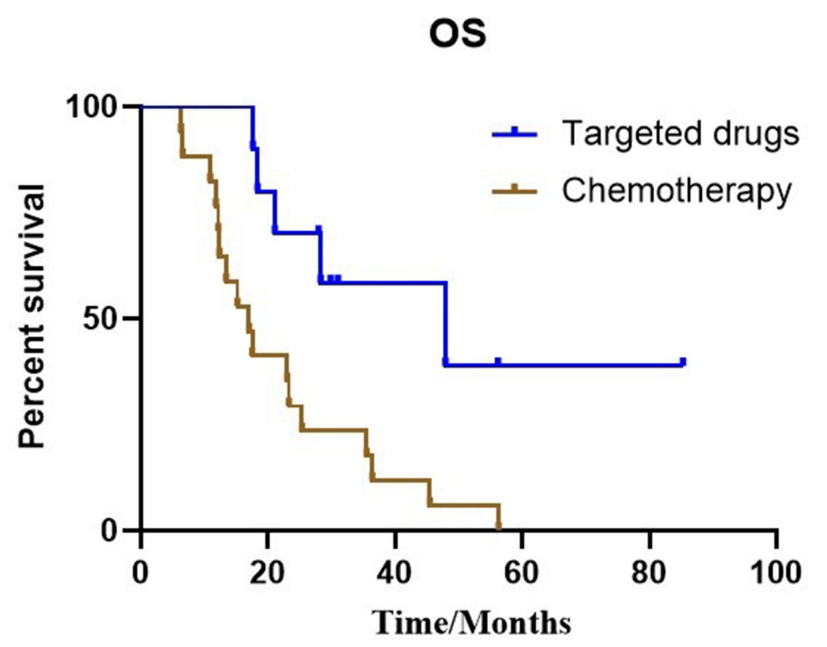

Figure 5 Kaplan-Meier estimates of overall survival according to different treatments in patients with cystic BM: targeted drugs and chemotherapy (47.9 months vs 17.0 months, $\mathrm{P}=0.007)$.

\section{Discussion}

Cystic BM is regarded as an important sign of poor prognosis in some types of cancer. ${ }^{9,10}$ However, controversy exists regarding the prognosis and treatment strategies for cystic BM in NSCLC. Only some retrospective studies examining cystic BM have demonstrated treatment results with brain radiotherapy. At present, there is a lack of large sample studies comparing the prognosis of solid BMs vs cystic BMs in NSCLC, and exploring the effects of chemotherapy or targeted therapy on cystic BM. Here, we found that cystic BM was more likely to occur in patients with lung cancer with genetic mutations, particularly EGFR mutation or ALK positive NSCLC. This is the 
first report to evaluate the efficacy of different treatment strategies for patients with NSCLC with cystic cerebral metastases.

The mechanism leading to the formation of cystic BM remains poorly understood. Studies have suggested that the cause of cystic masses may include the breakdown of the blood-brain barrier or the higher risk of developing cystic BM in patients with poor histological grade. ${ }^{10,11}$ In NSCLC, reports have demonstrated that patients with activating EGFR gene mutations have a higher risk of BM than those with wild type EGFR. ${ }^{12,13}$ In addition, initial BM occurs in approximately $30 \%$ of cases of ALKpositive NSCLC. ${ }^{14}$ We found that the incidence of cystic BM in EGFR and ALK gene positive NSCLC was higher than that in gene negative patients. Therefore, gene positive patients might have greater malignancy than gene negative patients and might be more prone to cystic BM. Rapid growth may be another possible reason underlying the generation of cystic components. Some studies have reported that cystic $\mathrm{BM}$ is more frequent in patients with NSCLC with ALK rearrangement. ${ }^{15-20}$ However, data regarding Chinese populations are lacking. In our research, through gene detection, we found that the incidence of cystic BM in EGFR mutated NSCLC was $80.0 \%(16 / 20)$ and that in ALK positive NSCLC was 20.0\% (4/20) among patients with adenocarcinoma. Currently, only one case has been reported involving EGFR mutation in NSCLC, in a patient who experienced a fatal cystic change in $\mathrm{BM}^{21}$ In the future, this area is worthy of further exploration and confirmation.

According to our results, systemic treatment strategies were the main factor affecting efficacy and prognosis. In patients with NSCLC with genetic mutation, targeted drug therapy improved brain efficacy and prolonged survival. Some reports have shown that ALK positive patients with NSCLC with cystic BM respond to ALK-TKI. ${ }^{14-20}$ Thus, a good response to agents targeted to specific driver oncogenes might potentially result in cystic degeneration of BM. Our research also showed that the efficacy of targeted drugs in patients with cystic BM was significantly higher than that of chemotherapy. The iPFS of patients with solid BM treated by chemotherapy was significantly longer than that in patients in the cystic BM cohort. In contrast, with treatment with targeted regimes, the iPFS in these two cohorts showed no significant difference. Targeted therapy was associated with a longer PFS. Therefore, we believe that targeted regimens are a better treatment for cystic BM. We further explored the correlations among progression pattern, efficacy and prognosis, and the results demonstrated that PFS in patients with brain lesion progression first was significantly poorer than that in patients with extra-cerebral lesions first.

Brigell et $\mathrm{al}^{22}$ compared the local control after braindirected radiation in patients with cystic vs solid BM, and found that patients with cystic BM have poorer local control after receiving stereotactic radiation. Nevertheless, the authors did not observe differences in oncologic outcomes between patients with at least one cystic BM and patients with all-solid BMs. Wang et $\mathrm{al}^{23}$ compared the survival between cystic and solid BM and assessed OS in patients who underwent radiosurgery treatment. They also found no difference in survival times between cystic and solid brain tumors, and suggested that radiosurgery may be a suitable treatment option for cystic BM. These findings indicate that cystic BM may not necessarily be a factor in poor prognosis. However, these two studies included different primary cancers, and the gene status in lung cancer patients was not complete. Moreover, the available treatments other than radiotherapy were unclear but might have affected the overall prognosis. Therefore, in our study, we further explored the value of radiotherapy in the treatment process for patients with cystic BM. We found no differences in outcomes depending on whether patients received brain radiotherapy. Of course, whether the patients had BM symptoms and the role of brain radiotherapy must be considered. In the future, additional prospective data will be needed to explore the radiotherapy mode and treatment timing.

Our results showed that targeted therapy is a key treatment for improving the prognosis of patients with cystic BM. The median OS of patients with cystic BM treated with targeted regimens was significantly longer than that of patients in the solid BM cohort; thus, patients with cystic BM may benefit from targeted therapy to a similar or greater extent than those with solid BM. This aspect is one of the most substantial differences between NSCLC and other cancers, thus leading to the different prognoses of patients with cystic BM in NSCLC. The specific mechanism still needs further exploration. Therefore, in the era of individualized treatment, patients should be genetically tested as much as possible to identify more suitable drug therapies.

Although this is the first study to evaluate the efficacy of different treatment strategies in patients with NSCLC with cystic cerebral metastases, the limitations of our 
study must be discussed. The retrospective nature of this study, including the heterogeneity among patients and lines of therapy, might have influenced some results. Moreover, the number of patients with cystic BM was small, thus potentially affecting the final results. In the future, further exploration of the relationship between target drugs and the radiotherapy mode or timing should be performed. Prospective studies with larger patient populations are needed for validation.

In conclusion, our study demonstrated that patients with NSCLC with genetic mutations might be more likely to have cystic BM. These patients should be genetically tested as much as possible to find more suitable drug therapies and identify patients with good prognosis who could potentially receive targeted drugs.

\section{Data Sharing Statement}

The data that support the findings of this study are available from the corresponding author upon reasonable request.

\section{Ethical Approval Statement}

The study was approved by the Zhejiang Cancer Hospital and the hospital's ethics committee, and it was conducted in strict accordance with the principles of the Declaration of Helsinki (as revised in 2013). Individual consent for this study was waived because this was a retrospective analysis, and the choice of therapeutic strategies was not interfered with. A statement covering patient data confidentiality was fully respected during data collection and the preparation of the manuscript.

\section{Author Contributions}

All authors made a significant contribution to the work reported, whether that is in the conception, study design, execution, acquisition of data, analysis and interpretation, or in all these areas; took part in drafting, revising or critically reviewing the article; gave final approval of the version to be published; have agreed on the journal to which the article has been submitted; and agree to be accountable for all aspects of the work. All authors revised the manuscript for important intellectual content. All authors reviewed and agreed to be accountable for all aspects of the work. All authors read and approved the final manuscript.

\section{Funding}

This work was supported by the Medical Health Science and Technology Project of the Zhejiang Provincial Health Commission (No. 2019RC027).

\section{Disclosure}

The authors declare no conflicts of interest in this article.

\section{References}

1. Siegel RL, Miller KD, Jemal A. Cancer statistics, 2017. CA Cancer J Clin. 2017;67:7-30. doi:10.3322/caac.21387

2. Nussbaum ES, Djalilian HR, Cho KH, Hall WA. Brain metastases. histology, multiplicity, surgery, and survival. Cancer. 1996;78:1781-1788. doi:10.1002/(SICI)1097-0142(19961015) 78:8<1781::AID-CNCR19>3.0.CO;2-U

3. Shi Y, Sun Y, Yu J, et al. [China experts consensus on the diagnosis and treatment of brain metastases of lung cancer (2017 version)]. Zhongguo Fei Ai Za Zhi. 2017;20:1-13. [Chinese].

4. Lombardi G, Di Stefano AL, Farina P, et al. Systemic treatments for brain metastases from breast cancer, non-small cell lung cancer, melanoma and renal cell carcinoma: an overview of the literature. Cancer Treat Rev. 2014;40:951-959. doi:10.1016/j.ctrv.2014.05.007

5. Owonikoko TK, Arbiser J, Zelnak A, et al. Current approaches to the treatment of metastatic brain tumours. Nat Rev Clin Oncol. 2014;11:203-222. doi:10.1038/nrclinonc.2014.25

6. Mehta MP, Rodrigus P, Terhaard CH, et al. Survival and neurologic outcomes in a randomized trial of motexafin gadolinium and whole brain radiation therapy in brain metastases. $J$ Clin Oncol. 2003;21:2529-2536. doi:10.1200/JCO.2003.12.122

7. Bulbul A, Forde PM, Murtuza A, et al. Systemic treatment options for brain metastases from non-small-cell lung cancer. Oncology. 2018;32:156-163.

8. Lim SH, Lee JY, Lee MY, et al. A randomized Phase III trial of stereotactic radiosurgery (SRS) versus observation for patients with asymptomatic cerebral oligo-metastases in non-small-cell lung cancer. Ann Oncol. 2015;26(4):762-768. doi:10.1093/annonc/mdu584

9. Uchino M, Nagao T, Seiki Y, et al. Radiosurgery for cystic metastatic brain tumor. No Shinkei Geka. 2000;28:417-421.

10. Gardner WJ, Collis JS, Lewis LA. Cystic brain tumors and the blood-brain barrier. Comparison of protein fractions in cyst fluids and sera. Arch Neurol. 1963;8:291-298. doi:10.1001/ archneur.1963.00460030075007

11. Sun B, Huang Z, Wu S, et al. Cystic brain metastasis is associated with poor prognosis in patients with advanced breast cancer. Oncotarget. 2016;7:74006-74014. doi:10.18632/oncotarget.12176

12. Sekine A, Kato T, Hagiwara E, et al. Metastatic brain tumors from non-small cell lung cancer with EGFR mutations: distinguishing influence of exon 19 deletion on radiographic features. Lung Cancer. 2012;77:64-69. doi:10.1016/j.lungcan.2011.12.017

13. Shin DY, Na II, Kim CH, et al. EGFR mutation and brain metastasis in pulmonary adenocarcinomas. $J$ Thorac Oncol. 2014;9:195-199. doi:10.1097/JTO.0000000000000069

14. Rusthoven CG, Doebele RC. Management of brain metastases in ALK-positive non-small-cell lung cancer. $J$ Clin Oncol. 2016;34:2814-2819. doi:10.1200/JCO.2016.67.2410

15. Grubb WR, Machtay M, Dowlati A, Biswas T. Diffuse atypical cystic brain metastases in ALK + NSCLC treated with whole brain radiation and second-generation ALK-targeted therapy. Pract Radiat Oncol. 2019;9:e129-e133. doi:10.1016/j.pro.2018.11.002

16. Marta GN, da Cunha Colombo Bonadio RR, Martins RE, et al. Cystic brain metastases in ALK-rearranged non-small cell lung cancer. Ecancermedicalscience. 2018;12:818.

17. Kim SH, Hyun JW, Kim HJ, et al. De novo cystic brain lesions mimicking neurocysticercosis in ALK-positive lung cancer. Lung Cancer. 2017;110:53-55. doi:10.1016/j.lungcan.2017.06.003

18. Saraceni C, Li PM, Gainor JF, et al. Cystic brain metastases in NSCLC harboring the EML4-ALK translocation after treatment with crizotinib. J Thorac Oncol. 2015;10:1116-1117. doi:10.1097/ JTO.0000000000000409 
19. Narayanan V, Honce MJ, Mehrotra S, Camidge DR. Cystic brain metastases occurring in anaplastic lymphoma kinase gene rearranged non-small-cell lung cancer patients receiving crizotinib. Clin Lung Cancer. 2016;17:85-90. doi:10.1016/j.cllc.2015.07.003

20. Hayashi H, Okamoto I, Tanizaki J, et al. Cystic brain metastasis in non-small-cell lung cancer with ALK rearrangement. J Clin Oncol. 2014;32:e122-e124. doi:10.1200/JCO.2012.48.2141

21. Zee YK, Chin TM, Wong AS. Fatal cystic change of brain metastasis after response to gefitinib in non-small-cell lung cancer. J Clin Oncol. 2009;27:e145-146. doi:10.1200/JCO.2009.22.4501
22. Brigell RH, Cagney DN, Martin AM, et al. Local control after brain-directed radiation in patients with cystic versus solid brain metastases. J Neurooncol. 2019;142(2):355-363. doi:10.1007/ s11060-019-03106-1

23. Wang H, Liu X, Jiang X, et al. Cystic brain metastases had slower speed of tumor shrinkage but similar prognosis compared with solid tumors that underwent radiosurgery treatment. Cancer Manag Res. 2019;11:1753-1763. doi:10.2147/CMAR.S188674

\section{Publish your work in this journal}

Cancer Management and Research is an international, peer-reviewed open access journal focusing on cancer research and the optimal use of preventative and integrated treatment interventions to achieve improved outcomes, enhanced survival and quality of life for the cancer patient.
The manuscript management system is completely online and includes a very quick and fair peer-review system, which is all easy to use. Visit http://www.dovepress.com/testimonials.php to read real quotes from published authors. 